\title{
ARENDT: LIBERDADE E TOTALITARISMO
}

José João Neves Barbosa Vicente ${ }^{1}$

Heleny Andrade Nunes ${ }^{2}$

\section{RESUMO}

O presente artigo visa analisar e refletir sobre o fenômeno totalitário na perspectiva de Arendt. É apontado neste trabalho de forma específica como a liberdade é sucumbida pelos modelos totalitários. Apresenta-se a problemática do totalitarismo de forma a propiciar reflexões e análises acerca das massificações contemporâneas. Contudo, se faz necessário relatar sobre o termo a unidade de representação do conceito da terminologia Totalitário, a historicidade que a envolve, bem como a puerilidade e a ação dos homens que viveram este modelo político.

Palavras-chave: Totalitarismo; Historicidade; Puerilidade; Ação; Liberdade.

\begin{abstract}
This article aims to analyze and reflect on the totalitarian phenomenon in the perspective of Arendt. It is pointed out in this work in a specific way how freedom is succumbed by totalitarian models. It presents the problems of totalitarianism to provide thoughts and analysis about the contemporary massification. However, it is necessary to report about the term the unit of representation of the concept of Totalitarian terminology, the historicity that it involves and the puerility and the action of men who have lived this political model.
\end{abstract}

Keywords: Totalitarianism; Historicity; Puerility; Action; Freedom.

\footnotetext{
${ }^{1}$ Professor Assistente da Universidade Federal do Recôncavo da Bahia.

${ }^{2}$ Graduada em Filosofia pela Universidade Federal do Recôncavo da Bahia. 
O presente artigo pretende refletir sobre o significado do fenômeno totalitário. Analisar conscientemente o fardo que se colocou sobre nós, sem negar sua existência, nem vergar humildemente ao seu peso. Compreender significa analisar como a liberdade foi sucumbida por este modelo, enxergar a realidade sem preconceitos e com atenção, e resistir para que não se torne presente entre nós. É preciso estar atento aos fatos da sociedade contemporânea, para que fatos vistos primeiramente como algo sem significância venham a tomar a dimensão do terror e da degradação humana.

Pensar em liberdade em Hannah Arendt é refletir sobre o poder de criar-se o novo, o começo é a suprema capacidade do homem: politicamente equivale à liberdade do homem. Por esse olhar, a persuasão permanente do modelo totalitário busca transformar as diferenças em monotonia. História que a levou a sua militância prática, falar sobre a sociedade. Tal discussão encontra formações basilares em tempos longínquos, desde as duas guerras mundiais, intercaladas de outras guerras locais, e revoluções que conduziram assim a uma terceira guerra mundial.

Esperança e tranquilidade não mais fazendo parte da ordem do mundo, nem pelas massas adornadas com a violência, desprovidas de lar e raízes. A instabilidade do futuro nunca antes dependeu tão intensamente dos políticos, que poderiam fugir às regras a qualquer instante. Agir neste sentido passa a ter o mesmo significado de liberdade. Um homem não pode ser livre se não age segundo suas próprias escolhas. Contudo, a política totalitária tornou o homem impotente para interromper com as atrocidades exercidas por seus governantes. $\mathrm{O}$ amálgama provocado pelo regime totalitário na sociedade alemã possibilitou imbecilismo nas massas de forma totalitária; a síntese da cristalização em um único pensar e agir.

Práticas totalitárias coisificando o homem, constituindo as massas impensantes. Os campos de concentração existiram mesmo com dispositivos e procedimentos jurídicos; privando seres humanos de agir. A vida e a morte, vistos como elementos que se apresentam de forma a explicitar nos governos tiranos e déspotas. Idealizados por homens, no intuito de que o homem viesse a se tornar uma unidade gigantesca e fria, igual a um iceberg. 
A análise sobre o fenômeno totalitário na perspectiva da filósofa Hanna Arendt é apontado neste trabalho de forma específica, como a liberdade é sucumbida pelos modelos totalitários. Apresenta-se a problemática do totalitarismo de forma a propiciar reflexões e análises acerca das massificações contemporâneas. Contudo, se faz necessário relatar sobre o termo, a unidade de representação do conceito da terminologia "Totalitário".

De acordo com Vicente, em seu artigo Educação e totalitarismo, , o termo "totalitarismo" foi usado por Benito Mussolini, no século passado, na Itália, durante a segunda década, para descrever o Estado Fascista. Também usado por intelectuais e por marxistas para definir um regime político. O Estado Totalitário subordina a economia sob seu poder coercitivo, centraliza todo seu poder político e administrativo, exercendo sua autoridade em todos os níveis e aspectos da sociedade.

No final da Segunda Guerra Mundial e nos anos seguintes de pós-guerra o termo usado para o mal político, para a agressividade por dominância ou medo, era o imperialismo. Tanto o termo totalitarismo quanto o imperialismo assinalavam para a sede do poder, da dominação e do terror de um estado monopolizado. A partir dos anos 50 a nomenclatura Totalitarismo tomou o lugar do Imperialismo. Era uma nova definição para algo que verdadeiramente aconteceu e que não se pode perder no limbo de uma especulação qualquer.

Versa-se sobre a necessidade de compreender o Totalitarismo, de modo que ele não seja visto apenas como um fato passado, mas com possibilidade de apresentar-se no presente. Estar atento aos fatos políticos e analisar as suas dimensões para não nos depararmos com resultados idênticos aos da Alemanha nazista, em 1938, e a União Soviética, em 1930 com o estalinismo. A singularidade deste modelo de sociedade é possível, graças à adesão das massas, onde não há o interesse comum e determinado, segundo Arendt:

Os movimentos totalitários são possíveis onde quer que existam massas que, por um motivo ou outro, desenvolvam certo gosto pela organização política. As massas não se unem pela consciência de um interesse comum e falta-lhe aquela específica articulação de classes que se expressa em objetivos determinados, limitados e atingíveis. O termo massa só se aplica quando lidamos com pessoas que, simplesmente devido ao seu número, ou a sua indiferença, ou a sua mistura de ambos, não se podem integrar numa organização baseada no interesse comum, seja partido político, organização profissional ou sindicato de trabalhadores. Potencialmente, as massas existem em qualquer país e constituem a maioria das pessoas neutras e politicamente indiferentes, que 
nunca se filiaram a um partido e raramente exercem o poder do voto. (ARENDT, 1989, p.361)

As massas deixam-se levar pela ideologia do estado, no caso, de unicamente uma vontade soberana. Pessoas abdicam da vida, da liberdade e até mesmo de serem humanos, e são coisificados pela falta de ação diante da dominação. Formas monstruosas de um fenômeno que trouxe e poderá trazer à humanidade perplexidade com marca de originalidade.

Arendt demarca a conceituação do termo Totalitarismo de maneira a demonstrar a ideologia e o terror. O desígnio deste modelo é a destruição moral e jurídica dos indivíduos, através da dominação, da transformação da natureza humana . Propicia-se a ausência de espontaneidade e a coisificação surge como um retrato do pânico e da falta de liberdade. Uma maneira peculiar de fazer política. O líder age do interior para o exterior, como ilustra Arendt (1942, p.137), “é uma estrutura cebola", no seio está o dirigente e a sua volta seus admiradores. Essa imagem revela uma organização, cuja legitimidade do poder não vem nem de fora e nem de cima, mas de dentro. Todos que estão fazendo parte da trama política agem como se tudo estivesse no mais alto grau de normalidade, para que as massas também concebam essa imagem. De acordo com Vicente (2010, p.8), o totalitarismo destrói toda e qualquer ação autônoma do indivíduo e devora a sociedade civil. O indivíduo retirado de seu meio local ou religioso e mobilizado para o serviço do Estado. O totalitarismo destrói, também, todos os vestígios culturais e transforma a sociedade numa multidão de massa dócil à palavra e às ordens de um chefe. Todos os espaços de debates e de escolhas são também destruídos.

O Totalitarismo absorveu até mesmo a possibilidade de escolhas, através da destruição do espaço que era de todos, ou seja, o público perde sua identidade juntamente com estes indivíduos. A ação humana ${ }^{3}$ não é mais identificável nos seus seguidores, tampouco nos responsáveis pela execução de inocentes e menos ainda por parte de seus líderes.

A perplexidade que este regime causou e causa só foi possível devido ao número de pessoas que obedeciam e não questionavam. O extermínio e a intimidação sofridos por

\footnotetext{
${ }^{3}$ Para Arendt (1983, p.15), a ação é “a única atividade que se exerce diretamente entre os homens sem a mediação das coisas ou da matéria, corresponde à condição humana da pluralidade, ao fato de que homens, e não o Homem, vivem na terra e habitam o mundo".
} 
aqueles que não aderiam ao Regime Totalitário estava para além dos amedrontamentos, porque, jamais esses seres humanos recebiam aviso, por tudo que estava prestes a acontecer. Neste sentido Arendt escreve:

À primeira vista, isso parece confirmação tardia da velha teoria do bode expiatório, e é verdade que a vítima do terror moderno exibe todas as características do bode expiatório: no sentido objetivo é absolutamente inocente, porque nada fez ou deixou de fazer que tenha ligação com seu destino. (ARENDT, 1989, p.26)

A justificativa para tanto absurdo seria a inocência, motivo pelo qual a máquina do terror apresenta sua ideologia, a de garantir adeptos o suficiente para manter-se no poder. $\mathrm{O}$ terror passa a ser a justificativa tanto para a morte quanto para adesão ao regime. A vítima é possuidora de grande inocência, observado em todos seus aspectos, sem ter a menor possibilidade de desconfiar do que está prestes a acontecer com sua vida. Para Vicente (2011, p.45), o domínio total baseado na ideologia e no terror, esse projeto político dos regimes totalitários que pretende implantar um espaço onde os homens se tornam absolutamente desprovidos de mundo em seu caráter "comum" e "humano", não parece vingar-se. Pois, no "novo começo" temos a oportunidade, ou melhor, a capacidade de agirmos como se tivéssemos de fundar nossa existência de novo.

Mesmo diante de tanta atrocidade, o homem, sob o poder político totalitário, pode ou poderia esboçar qualquer atitude que o caracterizasse humano. Sua disposição natural para ação era sucumbida pelo projeto dos regimes, através do terrível mundo que possuía objetivos de destruição de convivência, de sobrevivência e compaixão. Os limites para a política totalitária ultrapassa qualquer pretensão de esboço de espontaneidade, fazer qualquer coisa, a qualquer momento, de qualquer maneira era simplesmente impensável. Neste sentido, Arendt descreve os Modelos Totalitários como:

[...] organizações maciças de indivíduos atomizados e isolados. Distinguem-se dos outros partidos e movimentos pela exigência de lealdade total, irrestrita, incondicional e inalterável de cada membro individual. Essa exigência é feita pelos líderes dos movimentos totalitários mesmo antes de tomarem o poder e decorre da alegação, já contida em sua ideologia, de que a organização abrangerá, no devido tempo, toda a raça humana. (ARENDT, 1989, p.373)

A sociedade ideologicamente pensada para a concretude da catástrofe, pronta para atender a seu fim maior, o domínio e o terror. Seres isolados de si mesmos e do mundo, sem substancial concreto. Subsídios que efetivaram os movimentos totalitários no século $\mathrm{XX}$, e 
que corroboraram para instalação de um governo que se distinguia dos seus governados. Um modelo político que não se perpetuou, apenas passou, mas deixou marcas na história da humanidade.

A inconstância das massas contribuiu de forma decisiva para que os regimes totalitários se apresentassem como algo em constante movimento, de si mesmos e de tudo à sua volta. $\mathrm{O}$ fato de demonstrarem adaptabilidade e falta de continuidade era o suficiente para os líderes crerem estarem definitivamente no poder. Contudo, não apenas as camadas mais pobres da sociedade se sentiam atraídas pelos Modelos Totalitários, a elite possuía pessoas interessadas em fazer parte deste sistema, como afirma Arendt,

O que perturba os espíritos lógicos mais que a incondicional lealdade dos membros dos movimentos totalitários e o apoio popular aos regimes totalitários é a indiscutível atração que esses movimentos exercem sobre a elite e não apenas sobre os elementos da ralé da sociedade. Seria realmente temerário à excentricidade artística ou ingenuidade escolástica o espantoso número de homens ilustres que são simpatizantes, companheiros de viagem ou membros registrados dos partidos totalitários. (ARENDT, 1989, p.376)

A conjecturada intelectualidade da elite, da classe média e até mesmo dos menos favorecidos não foi o suficiente para garantir que este modelo político não colocasse em prática o seu poder de destruição. Ele se alastrou de tal modo que os valores pensados e desejados eram o de aniquilamento, desordem e desmoronamento; a guerra estava tão presente quanto o sangue que corria nas veias daqueles homens.

Esses homens, após a guerra, lembravam-se dela de forma majestosa, afinal marcava a transformação das camadas sociais em uma grande massa. Nivelaram-se as camadas sociais, até que todos pensassem que a individualidade deveria ser suprimida pela paixão, dando espaço para universalidade. O devotamento do indivíduo das massas não concebia que era apenas mais uma peça daquele jogo, a ideia de coletividade poderosa era o rótulo que os sustentavam. Mundo que para Foucault era descrito como:

O grotesco é um dos procedimentos essenciais à soberania arbitrária. Mas vocês também sabem que o grotesco é um procedimento inerente à burocracia aplicada, que a máquina administrativa, com seus efeitos de poder incontornáveis, passa pelo funcionário medíocre, nulo, imbecil, cheio de caspa, ridículo, puído, pobre, impotente, tudo isso foi um dos traços essências das grandes burocracias ocidentais, desde o século XIX. (FOUCAULT, 2001, 16) 
O que se afirma deste tipo de política é o mesmo que se afirmam do Nazismo e do Fascismo, pessoas que agem sem refletir sobre o próprio agir, tornam-se máquinas para tornarem pessoas coisificadas. Assim que esses homens embruteciam-se e eram embrutecidos pela máquina do poder, que administravam até mesmo as necessidades mais ínfimas de cada indivíduo, renunciar-se a si mesmo, deixar a vida, ainda existente, sem consciência desprender forças para a configuração e materialização do mal. Condição que, para Arendt,

Não é idêntico à terra ou à natureza como espaço limitado para o movimento dos homens e condição geral da vida orgânica. Antes, tem a ver com o artefato humano, com o produto de mãos humanos, com os negócios realizados entre os que, juntos, habitam o mundo feito pelo homem. Conviver no mundo significa essencialmente ter um mundo de coisas interposto entre os que nele habitam em comum, como uma mesa se interpõe entre os que se assentam ao seu redor; pois, como todo intermediário, o mundo ao mesmo tempo separa e estabelece uma relação entre os homens (ARENDT, 1983, p.62)

As características da vida não apareciam diante daqueles que seriam a expressão mais verdadeira possível da existência humana. Os espaços que circulavam, já não poderiam ser descritos como lugar de pessoas, ou seres humanos, a condição da vida já não está entrelaçada com o pensar e muito menos com o agir. O que estava posto no mundo não estabelecia nenhuma relação com e entre os indivíduos que se encontravam tão perto e tão distantes ao mesmo tempo. Esta distância que separa e ao mesmo tempo torna seres humanos em qualquer coisa. Como Nádia Souki nos coloca:

Arendt comenta uma curiosidade: na cultura clássica, tanto a língua grega quanto a latina possuíam dois verbos para designar aquilo que chamamos uniformemente de "agir". Em ambos os casos, a ação ocorre em duas etapas diferentes: a primeira é um começo mediante o qual algo de novo vem do mundo, e a segunda é a continuação da ação. A palavra grega árkhein, que abarca o começar, o conduzir, o governar, ou seja, as qualidades proeminentes do homem livre, testemunha uma experiência na qual ser livre e ter a capacidade de começar algo novo coincidem. Aqui, ação e liberdade coexistem. $\mathrm{Se}$ o agir corresponde à faculdade humana de começar, de empreender, de tomar iniciativa, então agir e novidade estão em relação estreita. (SOUKI, 1998, p.98).

Práticas racistas antissemitas e imperialistas corroboraram para a expansão do sistema totalitário, do mesmo modo que a adoção das pessoas que constituíam as massas. A aniquilação dos indivíduos por um sistema, no qual seres humanos eram seres nus. 
A liberdade para o homem pode ser nomeada de direitos reconhecidos ao indivíduo, considerado isolado ou em grupo, diante o Estado; e se pensada filosoficamente, pode ser compreendida de maneira negativa como a ausência de submissão e servidão. Contudo, o Totalitarismo não via potencial entre os oprimidos, que lutavam em movimentos libertários. A possibilidade de abrirem mão de interesses individuais e passarem a lutar por interesses coletivos estava dissociada das atitudes e pensamentos dos déspotas Totalitários. Para Vicente (2009, p.13), a política, de um modo geral, passou a ser uma arte de esquecer e de destruir o indivíduo. Suas variações ao longo dos séculos apontam para uma negação do indivíduo que nunca foi percebido, concebido como tal, mas sempre como uma parcela, um fragmento na vontade dos líderes. O totalitarismo foi a demonstração exacerbada do triunfo absoluto e sem partilha de um universo admitido para construir uma vasta e imensa máquina homogênea, purificada, fixa, mantida dentro daquilo que foi o modelo absoluto em matéria de fixismo e de negação de todo o dinamismo.

Pautados nos modelos do nazismo e do estalinismo, o governo totalitário impôs às pessoas o não enfrentamento pela busca da liberdade. Tanto o nazismo através das questões de raça, no qual idealizava uma raça pura, como no comunismo em que as questões sociais econômicas deveriam ser fator preponderante na escolha de indivíduos para a vida e para a morte o fato de serem seres humanos não os livravam da condição de cadáveres vivos, ao contrário, eles apenas representavam o uno, um ser entre vários, serem características de grupo.

As atrocidades praticadas nos campos de concentração demonstravam quão possível era à mente humana ser tão cruel e destruidora. $\mathrm{O}$ homem foi transformado e deformado na sua condição de homem, ou seja, perdeu a identidade de si e dos outros que circundavam o mesmo ambiente. Não era possível ver a si e nem a mais ninguém, seu olhar havia apagado diante da existência, era preciso diante de todas as monstruosidades cortarem a possibilidade de diálogo. Para Vicente (2009, p.19), não é fácil perceber o regime totalitário, como algo sem alma ele aparece e assume o controle de todos. Ele suga lentamente o sangue dos indivíduos transformando-os em uma massa de cadáveres vivos, sem iniciativas próprias absolutamente aptas a uma obediência incondicional. 
A ruptura é inerente ao homem. Ele rompe-se da relação materna ultra-interina através do cordão umbilical, rompe as relações com as pessoas quando não mais as atrai ou quando não desperta algum interesse. Mas, ser livre também é inerente ao humano, até mesmo quando não quer mais a liberdade que lhe é permitida ele vai em busca de outras formas que considera ser a melhor forma de liberdade. Em sanatórios, clínicas para viciados ou até mesmo nas ruas, pessoas agem de formas ditas convencionais pela sociedade aparentando estar vivendo a plena liberdade ou pelo menos a desejada por quem está na situação escolhida. Escolhe viver assim por acreditar que está sendo livre desta maneira. Segundo, Franca

"Totius libertatis radix est igitur in ratione contituta". Diz profundamente Santo Tomás: A raiz da liberdade está na razão. Onde quer que haja uma faculdade de generalização capaz de julgar da apetibilidade das coisas, de julgar o seu próprio juízo, vendo se convém agir ou não agir. Agir de um ou outro modo, aí há necessariamente um apetite livre. "Toda a questão do livre arbítrio reduz-se a uma questão de juízo imposto, ou não, autônomo ou não". (SERTILLANGES). Podemos julgar livremente de qualquer bem, que é apetecível sob outro, julgar que agir pode ser um bem para nós sob um aspecto e sob outro não agir... Logo somos livres, e tão certamente livres, como é certo que somos racionais. (FRANCA, 1954, p.19).

O homem é tão certamente livre que pode escolher não mais querer viver livre ou ser livre quando the convier. A partir das suas ações e expressões julga-se se o individuo é livre ou não, mas se de algum modo ele decide não agir, afirma-se então que não é mais possuidor de liberdade. Na própria condição humana compreende-se a possibilidade e necessidade da ação, contudo ela pode ser e foi imputada pelos modelos políticos totalitários. Agir seria diante do Totalitarismo buscar a própria morte, a ação humana dos indivíduos jamais podiam produzir efeitos, robores e cadáveres vivos bastaram para que o regime se instalasse.

As manifestações do homem apresentam-se como as potencialidades criadoras, não devem deixar de existir, elas próprias apresentam as condições de possibilidade do exercício da liberdade, ou seja, no espaço da divergência, é que o próprio indivíduo impõe seus questionamentos, se a liberdade seria intransponível. Não obstante, Vivente (2009, p.4) afirma que, o reconhecimento da possibilidade de um "novo começo", de acordo com Arendt, significa, essencialmente, acreditar profundamente que o homem é capaz de romper e inaugurar, de fazer o improvável e o incalculável, de criar um "mundo novo": um mundo não totalitário, um mundo comum, um mundo de liberdade.

A ruptura concebida através da ação humana, capaz de dar ao homem a possibilidade de criar e recriar o novo, um mundo liberto da dor e do sofrimento presente nos regimes totalitários, reconhecer-se como livre, dono das suas ações, possível de escolher o que melhor the convier. 
José João Neves Barbosa Vicente

Heleny Andrade Nunes

Portanto, apenas o homem é o único ser, capaz de dar vida às instituições que irão lhe legitimar, de modo que a sociedade possa lhe reconhecer e não aniquilá-lo.

\section{Referências bibliográficas}

ARENDT, H. Origens do totalitarismo. Trad. Roberto Raposo. São Paulo: Companhia das Letras, 1989.

. A condição humana. Trad. Roberto Raposo. Rio de Janeiro: Forense, 1983.

Entre o passado e o futuro. Trad. Mauro W. Barbosa de Almeida. São Paulo:

Perspectiva, 1972.

FOUCAUlT. M. Os anormais: Curso no Collège de France; Trad. Eduardo Brandão. São Paulo. Martins Fontes, 2001.

FRANCA. L.S.J. Liberdade e determinismo. Orientação da vida humana. Livraria Agir Editora, Rio de Janeiro, 1954.

SOUKI N. Hannah Arendt e o paradigma do antiestado. Caderno da Escola do Legislativo, 4(7), p.95-119, 1998. Disponível em: http://dspace.almg.gov.br/bitstream/handle/11037/1366/001366.pdf?sequence=3. Acesso em: 22 jan. 2014 .

VICENTE, J.J.N.B. Educação e totalitarismo. Revista Saberes, Natal - RN, v. 1, n.4, junho 2010. Disponível em http://www.cchla.ufrn.br/saberes. Acesso em: 15 jan. 2014.

. O mal do século. Editora Vieira, Goiânia. 2009.

. Totalitarismo, educação e justiça: uma abordagem filosófica. Cruz das

Almas: EDUFRB, 2012.

. Hannah Arendt e o "milagre" da natalidade. Revista Synesis, v. 3, n. 1,

2011. Disponível em http://seer.ucp.br/seer/index.php/synesis/index. Acesso em 21 fev. 2014. 